\title{
The source of fatty acids incorporated into proliferating lymphoid cells in immune-stimulated lymph nodes
}

\author{
Caroline M. Pond* and Christine A. Mattacks \\ Department of Biological Sciences, The Open University, Milton Keynes, Buckinghamshire M K 7 6AA, UK
}

(Received 27 J une 2002 - Revised 40 ctober 2002 - Accepted 17 October 2002)

\begin{abstract}
To explore the hypothesis that proliferating lymphoid cells in immune-stimulated lymph nodes obtain nutrients locally from adjacent adipose tissue, adult guinea pigs were fed for 6 weeks on standard chow or on chow supplemented with $100 \mathrm{~g}$ suet, sunflower oil or fish oil $/ \mathrm{kg}$. All the guinea pigs ate standard chow for the last $5 d$, during which swelling of one popliteal lymph node was stimulated by repeated local injection of lipopolysaccharide. The fatty acid compositions of phospholipids in both popliteal and in several mesenteric lymph nodes, and of triacylglycerols in eleven samples of adipose tissue defined by their anatomical relations to lymph nodes, were determined by GC. The proportions of fatty acids in the phospholipids extracted from the stimulated popliteal node correlated best with those of triacylglycerols in the surrounding adipocytes, less strongly with those of adipocytes el sewhere in depots associated with lymphoid tissue, but not with those of nodel ess depots. The composition of triacylglycerols in the perinodal adipose tissue changed under local immune stimulation. We conclude that proliferating lymphoid cells in activated lymph nodes obtain fatty acids mainly from the triacylglycerols in adjacent perinodal adipose tissue. I mmune stimulation prompts changes in the fatty acid composition of the triacylglycerols of adipocytes in node-containing depots that equip the adipose tissue for provisioning immune responses. Such local interactions show that special ised adipocytes can act as an interface between whole-body and cellular nutrition, and may explain why mammalian adipose tissue is partitioned into a few large and many small depots.
\end{abstract}

Perinodal adipose tissue: Paracrine interactions: Adipocyte site-specific properties: Popliteal: Mesenteric

The proliferation of lymphocytes in lymph nodes in response to immune stimulation requires various nutrients, including fatty acids (Calder et al. 1994; M oussa et al. 2000). The composition, as well as the abundance, of fatty acids available to growing or proliferating lymphoid cells are important, since those incorporated into membranes can modulate cell mobility, cell signalling and tolerance for oxidative stress (Calder, 2001). Immune activation increases energy utilisation within minutes, but, especially if anorexia al so occurs, nutrients from the gut are insufficient to meet the demand after the first few hours. The lipids must come mainly from adipose tissue, but little is known about how the immune system stimulates their mobilisation. It is still generally believed that the lymphoid cells take up supplies from the blood in competition with other lipid-utilising tissues such as muscle (Thies et al. 1999). Some fatty acids are oxidised or converted into eicosanoids, but the majority are incorporated into the phospholipids (PL) of the extensive membranes of the newly formed lymphocytes (Calder $\&$ Newsholme, 1993; Calder et al. 1994).

A Imost all large mammalian lymph nodes are embedded in adipose tissue, and most adipose depots enclose one or more nodes (Pond, 1996). The triacylglycerols (TAG) of perinodal adipocytes contain more polyunsaturated fatty acids (PUFA; M attacks \& Pond, 1997), and fewer saturates, than those not associated with lymphoid tissue, and adipocytes are capable of selective release of fatty acids ( $R$ aclot et al. 1995). Several lines of evidence are consistent with the hypothesis that perinodal adipose tissue is specialised to provision the proliferation and activation of lymph node lymphoid cells during local, transient immune responses (Pond, 1999, 2003a,b). The adipose tissue associated with lymphoid tissues is postulated to intervene between wholebody nutrition and cellular nutrition, determining the composition of precursors that actually reach the cells that metabolise them. 
In the present paper, we investigate the core prediction of this hypothesis that newly formed lymphoid cells selectively take up fatty acids released from TAG in perinodal adipocytes. Fatty acids in adipose tissue TAG cannot easily be labelled by conventional means, as their turnover is too slow and only a tiny fraction of the contents of mature adipocytes is mobilised by lipolysis. Instead, we alter their relative abundance by manipulating the diet over several weeks and compare the composition of fatty acids incorporated into newly formed lymphoid cells with that of TAG in samples of adipose tissue defined by their anatomical relations to the activated lymph node.

\section{Materials and methods}

\section{Animals and tissue samples}

Adult Bolivian guinea pigs aged 8-12 months were bred and raised on breeding-grade guinea-pig chow (FD1; Special Diet Services, Witham, UK), which contained $34 \mathrm{~g}$ crude lipid $/ \mathrm{kg}$. For 6 weeks, groups of nine animals (five females, four males) were fed on this unmodified diet, or on similar chow to which $100 \mathrm{~g}$ suet, sunflower oil, or fish oil was added/kg (Mattacks et al. 2002). The fatty acid compositions of these diets are shown in Table 1 . Water with added vitamin $C(0.1 \mathrm{mg} / \mathrm{ml})$ was available ad libitum, and the animals also received hay every day, and cabbage, carrot and apple on $5 \mathrm{~d}$ per week.

Starting $5 \mathrm{~d}$ before killing, local inflammation of the left popliteal lymph node was induced by daily injections of lipopolysaccharide (LPS). LPS $(20 \mu \mathrm{g} / \mathrm{kg}$ body mass dissolved in sterile $25 \mathrm{~mm}$-PBS at pH 7.4) was injected subcutaneously into the left lower leg about $8 \mathrm{~mm}$ cranial to the calcaneus. To ensure that, as far as possible, the abundance and composition of blood-borne lipids were similar in all the animals, they were all fed the unmodified, standard chow during this $5 \mathrm{~d}$ period. A nimals were fasted for $18 \mathrm{~h}$ before death by overdose of pentabarbitone. The stimulated popliteal and four conspicuous mesenteric lymph nodes were dissected out and weighed. Following protocols described elsewhere (Mattacks et al. 2002; Pond \& Mattacks, 2002), perinodal, middle and remote samples of adipose tissue were dissected from both popliteal depots, together with perinodal and remote samples from the mesentery, and the regions of the greater omentum rich in ('perinodal'), or lacking ('remote') milky spots, the patches of lymphoid tissue interspersed among adipocytes (Shimotsuma et al. 1993). A sample was also taken from the perirenal depot, which in guinea pigs does not contain any lymph nodes and accounts for more than $20 \%$ of all dissectible adipose tissue. The sample sites were selected by an experienced operator (C.A.M.) entirely on the basis of the adipose tissue's anatomical relations to lymph nodes and other structures.

\section{Lipid extraction and separation and quantification of fatty acids}

The TAG from each of these samples and the PL from the lymphoid cells in the lymph nodes were extracted by sonication in chloroform - methanol $(2: 1, v / v)$ followed by centrifugation. The TAG and PL in the chloroform layer were separated by TLC in diethyl ether - hexane- acetic acid mixture (10:0:5:0:0.2, by vol.), then transmethylated by heating for $1 \mathrm{~h}$ at $70^{\circ} \mathrm{C}$ with $0.5 \mathrm{ml}$ boron trifluoride $(140 \mathrm{~g} / \mathrm{l}$ methanol) and $0.5 \mathrm{ml}$ hexane. The hexane phases were removed and dried under $\mathrm{N}_{2}$ and resuspended in $100 \mu \mathrm{l}$ hexane. Samples of $100-500 \mathrm{nl}$ were injected into an A lltech A ssociates (A pplied Science L td, Carnforth, Lancs., UK) AT-WAX column $(30 \mathrm{~m} \times 0.25 \mathrm{~mm} \times 0.25 \mu \mathrm{m})$ on a Perkin-Elmer A utosystem GC (Shelton, CT, USA) using $\mathrm{He}$ as the carrier gas. It was programmed for a gradual temperature increase from 170 to $220^{\circ} \mathrm{C}$ over $30 \mathrm{~min}$. Peaks amounting to $1 \%$ or more of the total counts were identified as: $14: 0,14: 1 n-5,15: 0,16: 0,16: 1 n-7,18: 0,18: 1 n-9$, $18: 2 n-6,18: 3 n-3$ for adipocyte TAG; $16: 0,16: 1 n-7$, $18: 0,18: 1 n-9,18: 2 n-6,18: 3 n-3,18: 3 n-6,20: 3 n-6$, $20: 4 n-6,20: 5 n-3,22: 6 n-3$ for lymphoid-cell PL.

\section{Statistical methods}

Data were analysed using SPSS (SPSS Inc., Chicago, IL, USA), Microsoft Excel (Microsoft Corporation, USA) and CricketG raph (CA-CricketGraph III, version 1.5; Computer Associates International Inc., Islandia, NY, USA) to calculate mean values, standard errors, ANOVA and Pearson's correlation coefficients on linear regressions. Significance was taken as $95 \%(P<0.05)$.

Table 1. Summary of the proportions ( $\mathrm{g} / 100 \mathrm{~g}$ total fatty acids extracted) of saturated $(14: 0,16: 0$ and $18: 0)$, monoenoic $(14: 1,16: 1$ and $18: 1)$ $n-6$ polyunsaturated $(18: 2,18: 3,20: 3$ and $20: 4)$ and $n-3$ polyunsaturated $(18: 3,20: 5$ and $22: 6)$ fatty acids in the triacylglycerols extracted from the standard chow and the supplemented chows ${ }^{\star} \dagger$

\begin{tabular}{lcccc}
\hline Diet & Saturated & Monoenoic & $n-6$ PUFA & $n$-3 PUFA \\
\hline Standard chow & 36.4 & 33.9 & 24.3 & 5.4 \\
+ Beef suet & 47.4 & 38.8 & 12.7 & 1.1 \\
+ Sunflower oil & 20.2 & 36.5 & 36.8 & 6.6 \\
+ Fish oil & 23.6 & 34.1 & 30.8 & 11.6 \\
\hline
\end{tabular}

PUFA, polyunsaturated fatty acid.

* For details of diets, see p. 376 .

†Standard chow (FD1; Special Diet Services,Witham, UK) contained $30 \mathrm{~g}$ digestible fat $/ \mathrm{kg}$; supplemented chow contained $130 \mathrm{~g}$ digestible fat $/ \mathrm{kg}$. 
Table 2. Body mass $(\mathrm{g})$ at death and the masses $(\mathrm{mg})$ of the lipopolysaccharide-stimulated (left) and the unstimulated (right) popliteal lymph nodes, and mesenteric lymph nodes from guinea pigs fed on standard chow or chow supplemented with beef suet, sunflower oil or fish oil.* The ratios of the masses of stimulated and unstimulated popliteal nodes, and of the stimulated popliteal to mesenteric nodes, are also shown (Mean values with their standard errors for nine guinea pigs per group)

\begin{tabular}{|c|c|c|c|c|c|c|c|c|c|c|c|c|}
\hline \multirow[b]{3}{*}{ Dietary group } & & & \multicolumn{6}{|c|}{ Popliteal lymph node } & \multirow{2}{*}{\multicolumn{2}{|c|}{$\begin{array}{l}\text { Mesenteric } \\
\text { lymph node } \\
(\mathrm{mg})\end{array}$}} & \multirow{2}{*}{\multicolumn{2}{|c|}{$\begin{array}{l}\text { Stimulated } \\
\text { popliteal: } \\
\text { mesenteric } \\
\text { lymph nodes }\end{array}$}} \\
\hline & \multicolumn{2}{|c|}{ Body mass (g) } & \multicolumn{2}{|c|}{$\begin{array}{l}\text { Stimulated } \\
\text { (mg) }\end{array}$} & \multicolumn{2}{|c|}{$\begin{array}{l}\text { Unstimulated } \\
\qquad(\mathrm{mg})\end{array}$} & \multicolumn{2}{|c|}{$\begin{array}{l}\text { Stimulated: } \\
\text { Unstimulated }\end{array}$} & & & & \\
\hline & Mean & SEM & Mean & SEM & Mean & SEM & Mean & SEM & Mean & SEM & Mean & SEM \\
\hline Standard chow & 886 & 75 & $13 \cdot 9$ & 1.23 & 1.9 & 0.11 & $7 \cdot 61$ & 0.82 & 4.24 & 0.64 & 3.59 & 0.35 \\
\hline + Beef suet & 1023 & 46 & $12 \cdot 8$ & 0.60 & $2 \cdot 3$ & 0.17 & $5 \cdot 72$ & 0.50 & 3.38 & 0.26 & 4.07 & 0.51 \\
\hline + Sunflower oil & 1137 & 80 & 14.4 & 0.87 & $3 \cdot 3$ & 0.29 & 4.68 & 0.60 & $3 \cdot 81$ & 0.29 & 3.97 & 0.44 \\
\hline + Fish oil & 981 & 66 & $15 \cdot 3$ & 0.87 & $3 \cdot 1$ & 0.20 & $5 \cdot 11$ & 0.50 & $3 \cdot 66$ & 0.22 & 4.25 & 0.28 \\
\hline
\end{tabular}

${ }^{*}$ For details of diets and procedures, see Table 1 and p. 376.

\section{Results}

\section{Morphological data}

Table 2 lists results obtained at dissection. As we have found previously (Mattacks \& Pond, 1997), differences in the body masses of the four dietary groups (nine guinea pigs per group) were not significant (ANOVA by diet, F $2 \cdot 242$, NS). Stimulation by repeated injection of LPS increased the mass of the adjacent popliteal lymph node by an average of sixfold, representing the formation of many new lymphoid cells. The locally stimulated (left) lymph node and the mesenteric Iymph nodes were similar in mass under all the dietary regimens (left popliteal F 1.39, mesenteric F $0.377 ; \mathrm{NS}$ ). The masses of the right (nonstimulated) popliteal lymph node differed between experimental groups ( $F 11.76, P<0.001$ ), being larger in guinea pigs fed on the sunflower-oil or fish-oil diets.

\section{F atty acid composition}

Table 3 summarises the fatty acid composition of the lymphoid and adipose tissues studied. The proportions were substantially different in PL extracted from lymph nodes and adipose TAG, but none of the differences between the stimulated popliteal and the mesenteric lymph nodes was significant. All the variances for the composition of

Table 3. The proportions of saturated $(14: 0,16: 0$ and $18: 0)$, monoenoic $(14: 1,16: 1$ and $18: 1), n-6$ polyunsaturated $(18: 2,18: 3,20: 3$ and $20: 4)$ and $n-3$ polyunsaturated $(18: 3$, $20: 5$ and $22: 6$ ) fatty acids in phospholipids extracted from the stimulated popliteal and the mesenteric lymph nodes, and from triacylglycerols in adipose tissue*

(Mean values with their standard errors for thirty-six guinea pigs: nine animals for each of the four treatment groups)

\begin{tabular}{|c|c|c|c|c|c|c|c|c|}
\hline \multirow[b]{3}{*}{ Sample } & \multicolumn{8}{|c|}{ Fatty acids (g/100 g) } \\
\hline & \multicolumn{2}{|c|}{ Saturated } & \multicolumn{2}{|c|}{ Monoenoic } & \multicolumn{2}{|c|}{$n-6$ PUFA } & \multicolumn{2}{|c|}{$n$-3 PUFA } \\
\hline & Mean & SEM & Mean & SEM & Mean & SEM & Mean & SEM \\
\hline \multicolumn{9}{|c|}{ Phospholipid fatty acids in lymph node(s) } \\
\hline Popliteal & $29 \cdot 3$ & 0.50 & 56.4 & 0.62 & $3 \cdot 3$ & 0.36 & $11 \cdot 0$ & 1.07 \\
\hline Mesenteric & $29 \cdot 2$ & 0.44 & $57 \cdot 3$ & 0.52 & $3 \cdot 0$ & 0.25 & $10 \cdot 5$ & $1 \cdot 00$ \\
\hline \multicolumn{9}{|c|}{ Triacylglycerol fatty acids in adipose tissue } \\
\hline \multicolumn{9}{|c|}{ Locally stimulated popliteal } \\
\hline Perinodal & $37 \cdot 2$ & 0.62 & $30 \cdot 5$ & 0.40 & $26 \cdot 0$ & 0.39 & $6 \cdot 4$ & 0.41 \\
\hline Middle & 38.7 & 0.75 & $31 \cdot 0$ & 0.42 & $24 \cdot 7$ & 0.53 & $5 \cdot 7$ & 0.39 \\
\hline Remote & $40 \cdot 5$ & 0.83 & $32 \cdot 6$ & 0.67 & $22 \cdot 2$ & 0.76 & $4 \cdot 7$ & 0.34 \\
\hline \multicolumn{9}{|c|}{ Unstimulated popliteal } \\
\hline Perinodal & 37.4 & 0.77 & $30 \cdot 7$ & 0.30 & 25.9 & 0.54 & $6 \cdot 0$ & 0.39 \\
\hline Middle & $41 \cdot 0$ & 0.95 & $30 \cdot 8$ & 0.37 & $23 \cdot 1$ & 0.62 & $4 \cdot 2$ & 0.37 \\
\hline Remote & $42 \cdot 0$ & 1.01 & $32 \cdot 5$ & 0.51 & $21 \cdot 4$ & 0.77 & $4 \cdot 1$ & 0.34 \\
\hline \multicolumn{9}{|l|}{ Mesenteric } \\
\hline Perinodal & $36 \cdot 2$ & 0.63 & $31 \cdot 0$ & 0.66 & $25 \cdot 9$ & 0.50 & $6 \cdot 9$ & 0.49 \\
\hline Remote & $41 \cdot 1$ & 1.05 & 32.5 & 0.47 & $22 \cdot 0$ & 0.76 & $4 \cdot 4$ & 0.38 \\
\hline \multicolumn{9}{|l|}{ Omental } \\
\hline Perinodal & $33 \cdot 6$ & 0.71 & $30 \cdot 8$ & 0.38 & $27 \cdot 2$ & 0.25 & $8 \cdot 5$ & 0.43 \\
\hline Remote & 40.5 & 0.97 & 33.4 & 0.47 & 21.8 & 0.81 & 4.4 & 0.32 \\
\hline Perirenal & $43 \cdot 0$ & 0.55 & 33.5 & 0.55 & $19 \cdot 8$ & 0.77 & $3 \cdot 8$ & 0.30 \\
\hline
\end{tabular}

PUFA, polyunsaturated fatty acid.

${ }^{*}$ For details of diets and definitions of sample sites, see Table 1 and p. 376. 
the newly formed PL in stimulated popliteal lymph nodes were higher than those for the mesenteric lymph nodes. The most variable category, as indicated by the values of the standard errors, was the n-3 PUFA.

A s intended, the four different diets also generated large differences between specimens in the composition of adipose tissue fatty acids, as indicated by the high standard errors for most values. The site-specific differences in compositions of adipose tissue TAG are similar to those reported previously in guinea pigs (Mattacks \& Pond, 1997) and rats, with the proportions of PUFA increasing, and that of saturates decreasing, with proximity to concentrations of lymphoid tissues. None of the differences between homologous samples from the locally stimulated and unstimulated popliteal depots for the whole cohort was significant. However, the results in Table 3 show a clear trend towards more PUFA in the adipose tissue that enclosed the stimulated lymph node.

The correlations between the composition of PL fatty acids in the newly formed lymphoid cells in the stimulated popliteal lymph node and other samples for the thirty-six guinea pigs are listed in Table 4. As expected, the composition of fatty acids in this tissue correlated highly significantly $(P<0.01)$ with that of $P L$ in mesenteric lymph nodes. All three categories of fatty acids extracted from neutral lipids in the perinodal adipose tissue surrounding the stimulated lymph node correlated with those of the newly formed lymphoid cells therein (Table 4), though the similarity with extracts from mesenteric lymph nodes was weaker (Table 5). The correlations between the compositions of neutral lipids and newly synthesised PL

Table 4. Correlations between the proportions of saturated, monoenoic and polyunsaturated fatty acids in phospholipids extracted from the stimulated popliteal lymph node and the mesenteric lymph nodes, and triacylglycerols in adipose tissue

(Correlation coefficients for data from thirty-six guinea pigs)

\begin{tabular}{|c|c|c|c|}
\hline \multirow[b]{2}{*}{ Source of fatty acids } & \multicolumn{3}{|c|}{$\begin{array}{l}\text { Correlation with composition of } \\
\text { phospholipids in the stimulated popliteal } \\
\text { lymph node }(r) \dagger\end{array}$} \\
\hline & $\%$ Saturated & $\%$ Monoenoic & $\%$ PUFA \\
\hline \multicolumn{4}{|c|}{ Phospholipid fatty acids in mesenteric lymph node } \\
\hline & $0.692^{\star \star}$ & $0.756^{\star \star}$ & $0.797^{\star *}$ \\
\hline \multicolumn{4}{|c|}{ Triacylglycerol fatty acids } \\
\hline \multicolumn{4}{|c|}{ Locally stimulated popliteal } \\
\hline Perinodal & $0.334^{*}$ & $0.437^{\star \star}$ & $0.596^{\star \star}$ \\
\hline Middle & 0.295 & $0.438^{* *}$ & $0.514^{\star *}$ \\
\hline Remote & 0.263 & $0.352^{\star}$ & $0.422^{\star \star}$ \\
\hline \multicolumn{4}{|l|}{ Unstimulated popliteal } \\
\hline Perinodal & 0.282 & 0.196 & $0.352^{*}$ \\
\hline Middle & 0.205 & 0.304 & 0.241 \\
\hline Remote & $0.403^{\star}$ & 0.177 & 0.144 \\
\hline \multicolumn{4}{|l|}{ Mesenteric } \\
\hline Perinodal & $0.355^{\star}$ & 0.123 & $0.332^{*}$ \\
\hline Remote & 0.032 & $0.369^{*}$ & 0.024 \\
\hline \multicolumn{4}{|l|}{ Omental } \\
\hline Perinodal & 0.223 & 0.116 & $0.386^{*}$ \\
\hline Remote & 0.123 & 0.057 & 0.272 \\
\hline Perirenal (nodeless) & 0.007 & 0.157 & 0.046 \\
\hline
\end{tabular}

PUFA, polyunsaturated fatty acid.

${ }^{\star} P<0.05,{ }^{\star \star} P<0.01$.

† df 34 . weaken with distance of the sample of adipose tissue from the popliteal lymph node, with only that for the proportion of PUFA being highly significant $(P<0.01)$ for the 'remote' sample.

All measures of fatty acid composition in both mesenteric and popliteal lymph nodes failed to correlate with those of the adipose tissue from the nodeless perirenal depot (Tables 4 and 5). Weak correlations were found between the composition of PL fatty acids in the stimulated popliteal lymph node and six out of the twenty-one other measures of composition of adipose tissue TAG (Table 4). Four of the correlations relate to perinodal samples, and half to PUFA. If significance is taken as $P<0.05$, then in about $5 \%$ of situations where there was no actual correlation, the correlation coefficients calculated would be expected to be spuriously significant.

The similarity between fatty acid composition of mesenteric lymph nodes and adipose tissue samples (Table 5) was generally weaker than for the popliteal (Table 4). The only statistically significant correlations between the composition of mesenteric lymphoid cells (Table 5) were with the unsaturated fatty acids in the samples from the adipose tissue enclosing the stimulated lymph node, particularly their PUFA. This similarity may arise from the slightly greater abundance of PUFA in the adipose tissue that enclosed the stimulated popliteal lymph node than in homologous samples from the unstimulated side (Table 3).

\section{Discussion}

\section{M ethods}

The use of dietary lipids as metabolic 'tracers' has the advantages of minimising stress on the experimental animals, which is important for experiments that depend

Table 5. Correlations between the proportions of saturated, monoenoic and polyunsaturated fatty acids in phospholipids extracted from the mesenteric lymph nodes and triacylglycerols in adipose tissue

(Correlation coefficients for data from thirty-six guinea pigs)

\begin{tabular}{llll}
\hline & \multicolumn{2}{c}{$\begin{array}{c}\text { Correlation with composition of phospho- } \\
\text { lipids in mesenteric lymph nodes }(r) \dagger\end{array}$} \\
\cline { 2 - 4 } Source of fatty acids & \% Saturated & \% Monoenoic & $\%$ PUFA \\
\hline $\begin{array}{l}\text { Locally stimulated popliteal } \\
\text { Perinodal }\end{array}$ & 0.270 & $0.387^{*}$ & $0.478^{\star *}$ \\
Middle & 0.215 & 0.235 & $0.372^{\star}$ \\
Remote & 0.108 & $0.357^{*}$ & $0.345^{\star}$ \\
Unstimulated popliteal & & & \\
Perinodal & 0.031 & 0.166 & 0.108 \\
Middle & 0.148 & 0.271 & 0.053 \\
Remote & 0.015 & 0.324 & 0.087 \\
Mesenteric & & & \\
Perinodal & 0.123 & 0.202 & 0.203 \\
Remote & 0.292 & 0.299 & 0.115 \\
Omental & & & \\
Perinodal & 0.155 & 0.076 & 0.267 \\
Remote & 0.043 & 0.026 & 0.034 \\
Perirenal (nodeless) & 0.163 & 0.214 & 0.162 \\
\hline
\end{tabular}

PUFA, polyunsaturated fatty acid.

${ }^{\star} P<0.05,{ }^{\star \star} P<0.01$.

† df 34. 
upon minor, local immune stimulation. Guinea-pig lymph nodes are very small (see Table 2 ) and the mass of perinodal adipose tissue is also only a few $\mathrm{mg}$. The popliteal lymph node was chosen for study because it can be stimulated locally by minimally invasive procedures. Radiolabelling of ingested tracers would entail using large quantities of radioactive isotopes, and injecting substances that would reliably and safely reach the mesenteric as well as both popliteal lymph nodes is impractical. M easuring the ratio of stable isotopes $\left({ }^{13} \mathrm{C}:{ }^{12} \mathrm{C}\right)$ would not necessarily have achieved greater accuracy in view of the very small quantities of materials available.

Even if lipolysis were continuously stimulated by cytokines secreted from the activated lymphoid cells in the lymph node, only a tiny fraction of the TAG in the perinodal adipocytes would be hydrolysed. Lipolysis can be selective (Raclot et al. 1995), so the fatty acids released may not be a representative sample of those left behind as TAG. Of the fatty acids secreted in the perinodal region, not all would be taken up by lymphoid cells (some would be re-esterified into the adipocytes, or enter the general blood circulation), and not all of those would be incorporated into PL in the lymph node: some would be oxidised or otherwise metabolised, or incorporated into lymphoid cells that migrate out of the node in blood or lymph. All these factors would reduce the similarity between the fatty acid composition of adipocyte TAG and Iymphoidcell PL, and confound all other tracer methods that depend upon marking fatty acids.

\section{Interpretation of results}

The morphological findings were similar to those reported previously (M attacks et al. 2002). The guinea pigs used in the present study were healthy and free from visible wounds or infection, so the popliteal lymph node would be quiescent (Smith $\&$ M orris, 1970). The total dose of LPS was only about $10 \%$ of that which would induce fever (Roth et al. 1994), but was sufficient to cause swelling of the adjacent popliteal lymph node. The experimental diets were supplemented with only $100 \mathrm{~g}$ fat $/ \mathrm{kg}$, only half as much as that used to modulate immune responses in murid rodents (Moussa et al. 2000; Wallace et al. 2000), but guinea pigs respond to lipid supplementation of the diet differently from rats (Murphy et al. 1999). Severe regimens of starvation and refeeding that have been used to increase the turnover of storage fatty acids (Lin et al. 1993) were not imposed.

The site-specific differences in compositions of adipose tissue TAG (Table 3) are similar to those reported previously in guinea pigs (Mattacks \& Pond, 1997) and rats (Priddle et al. 2003). They may arise from selective release of fatty acids from TAG (Raclot et al. 1995). Various membrane-associated proteins that could enable uptake of free fatty acids from plasma have been described (Stremmel et al. 2001), but a role in selective uptake has yet to be demonstrated. While the popliteal lymph node was enlarging under the influence of LPS, all the guinea pigs ate the same, unsupplemented chow ad libitum, thus homogenising as far as possible the abundance and composition of lipids that could be extracted from the blood by activated tissues. Nonetheless, the fatty acid composition of the PL in the stimulated popliteal lymph node, most of which would have been synthesised during this period, was as variable as that of the adipose tissue TAG (Table 3 ).

In contrast to proteins and nucleic acids, where the proportions of component molecules are tightly controlled, the composition of PL fatty acids is not precisely determined, and can vary even in tissues of very similar structure and function. Although all were significant, none of the correlation coefficients between the compositions of fatty acids extracted from the popliteal and mesenteric lymph nodes reached 0.8 (Table 4). The other correlation coefficients should be assessed against this background.

The cluster of highly significant correlations between the composition of the popliteal PL and those of the TAG in the contiguous adipose tissue (Table 4) supports the hypothesis that the latter is the source of the former. Lipolysis increases in perinodal adipocytes early in an immune response (Pond \& Mattacks, 1998), probably due to cytokines secreted by activated Iymphoid cells. Repeated immune stimulation raises lipolysis in the rest of nodecontaining depot within hours (Pond \& Mattacks, 2002). Possible mechanisms by which fatty acids so released could enter the adjacent lymph node are discussed elsewhere (Pond, 1996).

The composition of the newly formed lymphoid cells does not correlate at all with that of TAG in the large nodeless perirenal depot, although its adipocytes have a higher rate of lipolysis during fasting than any adipocytes associated with lymphoid tissue (Mattacks \& Pond, 1999) and hence, together with the current diet, must contribute most to blood-borne lipids. The adipose tissue around all large lymph nodes interacts in vitro with lymphoid cells (Pond \& Mattacks, 1995), and contains more PUFA (M attacks \& Pond, 1997), which would produce the greater similarity between the composition of such samples and lymphoid cells (Table 4).

The composition of the mesenteric lymph nodes correlates with that of the popliteal adipose tissue from the LPS-injected leg, but not with homologous samples associated with the unstimulated popliteal lymph node (Table 5). B efore the experiment began, the compositions of TAG in the two popliteal depots must have been similar, but the local immune stimulation induced changes in the composition of TAG, especially the PUFA, in the adjacent adipose tissue, making it resemble more closely that of PL in the lymphoid tissues. Changes in metabolism and manifestation of receptors have been demonstrated within a few hours of the start of immune stimulation (Pond \& M attacks, 2002), long before enlargement of associated lymph nodes can be detected. As precursors for eicosanoids as well as for membrane $\mathrm{PL}$ (Hwang, 2000), PUFA are essential to lymphoid cells. Such changes are probably quite slow under the conditions studied here, and may not have progressed to completion. This effect may contribute to the reported changes in fatty acid metabolism associated with prolonged immune activation, such as that caused by HIV (Decsi \& Koletzko, 2000), or chronic inflammatory conditions (Geerling et al. 1999). 
Paracrine relationship between adipose and Iymphoid tissues

These present results are consistent with the hypothesis (Pond, 1999, 2002, 2003a,b) that during immune responses, lymphoid tissue obtains fatty acids (and possibly other precursors) from adjacent adipose tissue, as predicted from previous reports of the special properties of perinodal adipocytes (Mattacks \& Pond, 1999; Pond, 1999; Mattacks et al. 2002). The present experiment supports the conclusion reached 50 years ago from studies of the histology of developing lymph nodes: 'There may be presumed to be an interaction between fatty tissue and Iymph nodes' (Gyllensten, 1950).

The results are not consistent with the long-established assumption (Clandinin et al. 1991) that the precursors of $\mathrm{PL}$ of newly formed cells are derived directly from the diet via blood-borne lipids. V ascularisation of the perinodal adipose tissue increases under chronic immune stimulation, but the process is very slow compared with the timescale of this experiment (M acQueen et al. 1999). Increased perfusion of both the inflamed lymph node and its surrounding adipose tissue would obliterate most of the changes induced by the supplemented diets in the inflamed tissues, replacing them with fatty acids derived from the plain diet. In fact, we found no significant differences between the average compositions of homologous samples taken from the inflamed and non-inflamed popliteal depots (Table 3 ).

The present experiments also identify an additional process by which the adipose tissue that is anatomically associated with lymphoid structures is adapted to provision adjacent lymphoid tissues: chronic inflammation induces changes in the composition of its storage TAG. Such processes may underlie the highly variable site-specific differences in fatty acid composition of adipose tissue found in adult human subjects ( $\mathrm{M}$ alcom et al. 1989; Calder et al. 1992).

\section{The comparative anatomy of adipose tissue}

All living mammals (including the most primitive species) differ from other vertebrates in their anatomical organisation of both the peripheral lymphoid tissues and adipose tissue: the numerous widely dispersed lymph nodes are almost always associated with a small quantity of adipose tissue (Diener, 1970; Henry \& Symmers, 1992), and the adipose tissue is partitioned into a few large and many small depots. The evolutionary origins and function of these unique features of mammals are poorly understood (Pond, 2003a). We propose that they are functionally related and evolved hand-in-hand: specialisation of adipocytes for paracrine interactions with lymphoid tissues provisions, and possibly regulates, their activities locally. The contiguity of the provider and user tissues emancipates the lymphoid cells from competition for blood-borne nutrients secreted by 'general purpose' adipose depots, and enables local immune responses to be prompt and efficient. More efficient peripheral immune responses may have accompanied the evolution of homeothermy, fur replacing scales and the prolonged intimacy between mother and sucking young that would hasten the transmission and establishment of pathogens.

Paracrine interactions may also be the functional basis for the intimate association between many minor depots of adipose tissue and skeletal or cardiac muscle (Pond, 1992; Goodpaster et al. 2000). Like perinodal adipose tissue, intermuscular fat seems to be selectively conserved; its abundance and arrangement are normal in people with severe lipodystrophy of the subcutaneous depots (Garg et al. 1999). Prolonged, strenuous exercise induces skeletal muscle to produce (Jonsdottir et al. 2000) and secrete surprisingly large quantities of interleukin 6 and other cytokines that also coordinate aspects of immune responses (Pedersen et al. 2001), including the recruitment of adipocytes to local control by activated lymph nodes (M attacks $\&$ Pond, 1999). Specialised membrane proteins transport fatty acids into skeletal muscle (Luiken et al. 2000). These responses may be the basis for the redirection of lipid fuels between competing tissues. Because muscle oxidises most of the fatty acids it takes up rather than incorporating them into cells, establishing their anatomical source would be technically more difficult. A proliferating tissue that consists of numerous very small, membrane-rich cells and stays concentrated in the lymph nodes presents a better opportunity for demonstrating the paracrine transmission of fatty acids from adipocytes to the user tissue.

\section{Conclusions}

We conclude that the principal source of fatty acids for activated, proliferating lymphoid cells is TAG in the surrounding adipocytes, with the perinodal adipocytes making the largest contribution. Immune stimulation induces changes in the fatty acid composition of TAG in adipocytes in node-containing depots by mechanisms yet to be elucidated. These results are consistent with the hypothesis (Pond, 1999, 2002, 2003a,b) that adipose tissue in node-containing depots provisions lymphoid tissue. Paracrine interactions between adipocytes and contiguous tissues may explain why mammalian adipose tissue is partitioned into a few large, physiologically unspecialised depots and numerous small depots, many of which have site-specific biochemical properties appropriate for local interactions with adjacent tissues.

\section{Acknowledgements}

This research was partially supported by a consumables grant from The Leverhulme Trust. We thank Dawn Sadler for breeding and maintaining the guinea pigs, $\mathrm{Dr}$ Willem vas Dias (Seven Seas Ltd, Marfleet, Kingston upon Hull, UK) for the gift of fish oil for the guinea pigs' diet, and Dr J. D. Priddle and Dr R. H. Colby for helpful comments.

\section{References}

Calder PC (2001) The effect of dietary fatty acids on the immune response and susceptibility to infection. In Nutrition, Immunity, and Infection in Infants and Children, pp. 137-172 
[RM Suskind and $K$ Tontisirin, editors]. Philadelphia, PA: Lippincott, Williams \& Wilkins.

Calder PC, Harvey DJ, Pond CM \& Newsholme EA (1992) Sitespecific differences in the fatty acid composition of human adipose tissue. Lipids 27, 716-720.

Calder PC \& Newsholme EA (1993) Effects of omega-3 fatty acids on lymphocyte functions. In Omega-3 Fatty Acids: Metabolism and Biological Effects, pp. 293-303 [CA Drevon, I B aksaas and HE Krokan, editors]. Basel: Birkhäuser Verlag.

Calder PC, Y aqoob P, Harvey DJ, Watts A \& Newsholme EA (1994) Incorporation of fatty acids by concanavalin-A stimulated lymphocytes and the effect on fatty acid composition and membrane fluidity. Biochemical Journal 300, $509-518$.

Clandinin M T, Cheema S, Field CJ, Garg M L, V enkatraman J \& Clandinin TR (1991) Dietary fat: exogenous determination of membrane structure and cell function. FASEB Journal 5, 2761- 2769.

Decsi T \& Koletzko B (2000) Effects of protein-energy malnutrition and human immunodeficiency virus-1 infection on essential fatty acid metabolism in children. Nutrition 16, 447- 453.

Diener E (1970) Evolutionary aspects of immunity and lymphoid organs in vertebrates. Transplantation Proceedings $\mathbf{2}$ $309-317$.

Garg A, Peshock RM \& Fleckenstein JL (1999) A dipose tissue distribution pattern in patients with familial partial lipodystrophy (Dunnigan variety). Journal of Clinical Endocrinology and M etabolism 84, 170-174

Geerling BJ, van Houwelingen AC, Badart-Smook A, Stockbrugger RW \& Brummer JM (1999) Fat intake and fatty acid profile in plasma phospholipids and adipose tissue in patients with Crohn's disease, compared with controls. American J ournal of Gastroenterology 94, 410-417.

Goodpaster BH, Thaete FL \& K elley DE (2000) Composition of skeletal muscle evaluated with computed tomography. Annals of the New York Academy of Sciences 904, 18-24.

Gyllensten L (1950) The postnatal histogenesis of the lymphatic system of guinea-pigs. Acta Anatomica 10, 130-160.

Henry K \& Symmers W SC (1992) Thymus, Lymph Nodes, Spleen and Lymphatics, 3rd ed. Edinburgh: Churchill Livingstone.

Hwang D (2000) Fatty acids and immune responses - A new perspective in searching for clues to mechanism. Annual Review of Nutrition 20, 431 - 456

Jonsdottir IH, Schjerling $P$, Ostrowski $K$, Asp S, Richter EA \& Pedersen BK (2000) M uscle contractions induce interleukin- 6 mRNA production in rat skeletal muscles. J ournal of Physiology, London 528, 157- 163.

Lin DS, Connor WE \& Spenler CW (1993) A re dietary saturated, monounsaturated, and polyunsaturated fatty acids deposited to the same extent in adipose tissue of rabbits? American J ournal of Clinical Nutrition 58, 174-179.

Luiken JJFP, Glatz JFC \& Bonen A (2000) Fatty acid transport proteins facilitate fatty acid uptake in skeletal muscle. Canadian J ournal of Applied Physiology 25, 333-351.

M acQueen HA , Waights V \& Pond CM (1999) V ascularisation in adipose depots surrounding immune-stimulated lymph nodes. J ournal of Anatomy, London 194, 33-38.

Malcom GT, B hattacharyya AK, V elez-Duran M, Guzman MA, Oalmann MC \& Strong JP (1989) Fatty acid composition of adipose tissue in humans, differences between subcutaneous sites. American Journal of Clinical Nutrition 50, 288- 291.

Mattacks CA \& Pond CM (1997) The effects of feeding suetenriched chow on site-specific differences in the composition of triacylglycerol fatty acids in adipose tissue and its interactions in vitro with Iymphoid cells. British Journal of Nutrition 77, 621-643.

M attacks CA \& Pond CM (1999) Interactions of noradrenalin and tumour necrosis factor- $\alpha$, interleukin- 4 and interleukin- 6 in the control of lipolysis from adipocytes around lymph nodes. Cytokine 11, 334-346.

M attacks CA, Sadler D \& Pond CM (2002) The effects of dietary lipids on adrenergically stimulated lipolysis in perinodal adipose tissue following prolonged activation of a single lymph node. British Journal of Nutrition 87, 375-382.

Moussa M, Tkaczuk J, Ragab I, Garcia J, A bbal M, Ohayon E, Ghisolfi J \& Thouvenot JP (2000) Relationship between the fatty acid composition of rat lymphocytes and immune functions. British J ournal of Nutrition 83, 327- 333.

M urphy M G, W right V, Scott J, Timmins A \& Ackman RG (1999) Dietary menhaden, seal, and corn oils differentially affect lipid and ex vivo eicosanoid and thiobarbituric acid-reactive substances generation in the guinea pig. Lipids 34, 115- 124.

Pedersen BK, Steensberg A, Fischer C, Keller C, Ostrowski K \& Schjerling $P$ (2001) Exercise and cytokines with particular focus on muscle-derived IL-6. Exercise Immunology Reviews 7, 18-31.

Pond CM (1992) An evolutionary and functional view of mammalian adipose tissue. Proceedings of the Nutrition Society 51, 367- 377.

Pond CM (1996) Interactions between adipose tissue and the immune system. Proceedings of the Nutrition Society 55, $111-126$.

Pond CM (1999) Physiological specialisation of adipose tissue. Progress in Lipid Research 38, 225-248.

Pond CM (2002) A dipose tissue, the immune system and exercise fatigue: how activated Iymphocytes compete for lipids. Biochemical Society Transactions 30, 270-275.

Pond CM (2003a) Paracrine interactions of mammalian adipose tissue. J ournal of Experimental Zoology 295A, 99-110.

Pond CM (2003b) Paracrine relationships between adipose and lymphoid tissues: implications for the mechanism of HIVassociated adipose redistribution syndrome. Trends in Immunology 24, 13-18.

Pond CM \& M attacks CA (1995) Interactions between adipose tissue around lymph nodes and lymphoid cells in vitro. J ournal of Lipid Research 36, 2219-2231.

Pond CM \& M Mattacks CA (1998) In vivo evidence for the involvement of the adipose tissue surrounding lymph nodes in immune responses. Immunology Letters 63, 159- 167.

Pond CM \& M attacks CA (2002) The activation of adipose tissue associated with lymph nodes during the early stages of an immune response. Cytokine 17, 131-139.

Priddle JD, Mattacks CA, Sadler D, MacQueen HA \& Pond CM (2003) Changes in lymphokine receptor expression and fatty acid composition of phospholipids and triacylglycerols in rat adipocytes associated with lymph nodes following a transient immune challenge. Cell Biology International 27, 23- 29.

Raclot T, M ioskowski E, Bach AC \& Groscolas R (1995) Selectivity of fatty acid mobilization: a general metabolic feature of adipose tissue. American Journal of Physiology 269, R 1060 - R 1067

Roth J, M cClellan JL, K luger M J \& Zeisberger E (1994) Attenuation of fever and release of cytokines after repeated injections of lipopolysaccharide in guinea-pigs. J ournal of Physiology, London 477, 177- 185.

Shimotsuma M, Shields JW , Simpson-M organ M W , Sakuyama A, Shirasu M, Hagiwara A \& Takahashi T (1993) M orpho-physiological function and role of omental milky spots as omentumassociated lymphoid tissue (OALT) in the peritoneal cavity. Lymphology 26, 90-101. 
Smith JB \& M orris B (1970) The response of the popliteal lymph node of the sheep to swine influenza virus. Australian J ournal of Experimental Medicine 48, 47- 55.

Stremmel W, Pohl J, Ring A \& Herrmann T (2001) A new concept of cellular uptake and intracellular trafficking of long-chain fatty acids. Lipids 36, 981-989.

Thies F, Peterson LD, Pow ell JR, Nebe-von-Caron G, Hurst TL, Matthews KR, Newsholme EA \& Calder PC (1999)
Manipulation of the type of fat consumed by growing pigs affects plasma and mononuclear cell fatty acid compositions and Iymphocyte and phagocyte functions. Journal of Animal Science 77, 137-147.

Wallace FA, Miles EA \& Calder PC (2000) Activation state alters the effect of dietary fatty acids on pro-inflammatory mediator production by murine macrophages. Cytokine 12, 1374- 1379. 